\title{
Letter to the Editor: doubts and considerations about Coronary Syndrome
}

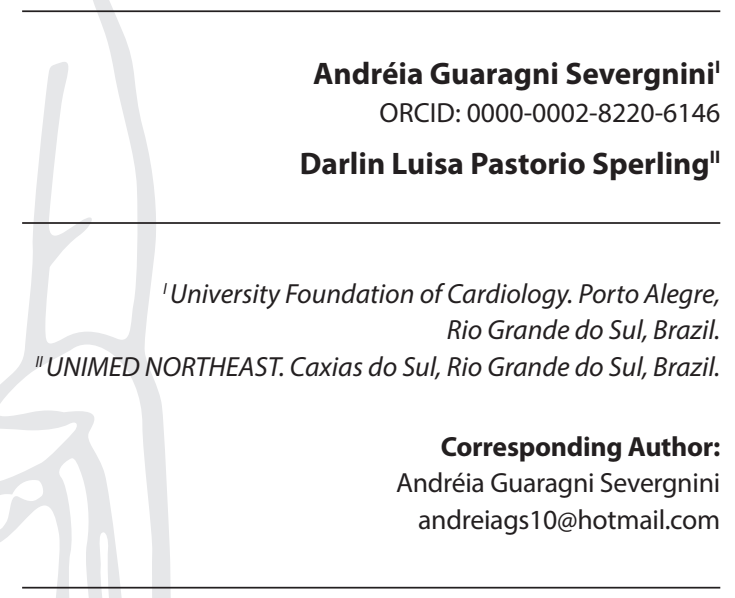

Corresponding Author: andreiags10@hotmail.com
Dear Editor,

We wrote this letter referring to the article "Impact of anxiety and depression on morbidity and mortality of patients with coronary syndrome" $\mathrm{e}^{\prime \prime(1)}$ to make some comments, in order to clarify doubts that we were missing from answering. We have already made it clear that our intention is not to question the work of the authors, not least because we consider ourselves new to scientific research, but we believe that this is a moment of learning. This moment allows us to question, opine, debate and understand that we are collaborating to enrich our learning.

In the introduction, the authors state that they did not find in the national literature subjects related to this theme. We were intrigued and decided to do a quick search in the national literature and found at least three studies related to this theme ${ }^{(2-4)}$. Perhaps the descriptors were placed inappropriately in searches of national literature. We suggest searching through the following descriptors: acute myocardial infarction, depression, quality of life, risk factors, acute coronary syndrome ${ }^{(5)}$.

In the method (design, study location and period), it is said that the study is a retrospective cohort of a previous study carried out in 2012. When looking for the reference on this previous study, we found none in the current work. The only reference found was that of a study conducted at the Pontifícia Universidade Católica do Rio Grande do Sul. However, the present study was carried out at the Coronary Unit of the Hospital das Clínicas' Heart Institute, linked to the Faculty of Medicine of Universidade de São Paulo. It was a little confusing which was the previous study used ${ }^{(6-7)}$.

Within the sample, we also believe that there was a significant segment loss (28\%) for a study of this complexity. In other studies cited by the authors, the samples were much larger. Initially, the previous study had 120 patients, and after this loss, it ended with 96 patients. The authors themselves agreed at some point that the sample should be larger, since the statistical significance of the results may have been compromised ${ }^{(8-9)}$.

In addition, age is considered an important factor in the prognosis of cardiovascular diseases, since the greater the age, the greater the number of events. Because of this, we suggest a division by age groups, as this would bring a greater contribution to the study proposal ${ }^{(10)}$. In the study protocol, morbidity and mortality, right after discharge, one year after and two years after, were verified using data collected from the patients' electronic medical record. When such information was not found, telephone contact was made. The question is: who answered the questions when the telephone contact was made? (patient, relative, friend, caregiver...?) What types of questions were asked? The first study was carried out in 2012 and the current one in 2016, could there be any doubts as to the responses of the patients due to the elapsed time, to their own health and emotional state? 
The low number of patients with moderate/severe symptoms of depression and anxiety in this study can be explained by their average age. Young adults affected by ACS report more frequently the presence of feelings like anxiety and depression compared to the elderly ${ }^{(10)}$.

Concerning follow-up time, the authors cite studies with a follow-up of 10 years and more ${ }^{(11-12)}$, unlike the present study, with a 2-year follow-up. It is understood that a longer follow-up period, combined with an objective and comprehensive assessment of readmissions and mortality related to cardiovascular diseases, could contribute to achieving the proposed objective of this study.

We believe this study is very relevant to health. As professionals in the field, we would like to receive the authors' feedback on our doubts and that perhaps they could expand this study, to have more scientifically robust data. In advance, we appreciate the opportunity.

\section{REFERENCES}

1. Altino DM, Martins LAN, Gonçalves MAB, Barros ALBL, Lopes JL. Impact of anxiety and depression on morbidity and mortality of patients with coronary syndrome. Rev Bras Enferm [Internet]. 2018;71(6):3048-53. doi: 10.1590/0034-7167-2017-0709

2. De Mattos MA, Lougon M, Tura BR, Pereira BB. Depressão e Síndrome Isquêmica Coronariana Aguda. Instituto Nacional de Cardiologia Laranjeiras, Universidade Federal do Rio de Janeiro vol 18 n 4 pg 2882005

3. Alves TCTF, Fráguas R, Wajngarten M. Depressão e infarto agudo do miocárdio. Rev Psiquiatr Clín. 2009;36(3):88-92 São Paulo. doi: 10.1590/ S0101-60832009000900004

4. Lemos C, Gottschall CAM, Pellanda LC, Müller M. Associação entre depressão, ansiedade e qualidade de vida após infarto do miocárdio. Psic: Teor Pesq. 2008;24(4):471-6. doi: 10.1590/S0102-37722008000400010.

5. Biblioteca virtual em saúde. Descritores em ciências da saúde [Internet]. 2020[cited 2020 May 2]. Available from: www.decs.bvs.br

6. Lopes JL, Barbosa DA, Nogueira-Martins LA, Barros ALBL. Nursing guidance on bed baths to reduce anxiety. Rev Bras Enferm. 2015;68(3):437-43. doi: 10.1590/0034-7167.2015680317i

7. Meneghetti CC, Guidolin BL, Zimmermann PR, Sfoggia A. Screening for symptoms of anxiety and depression in patients admitted to a university hospital with acute coronary syndrome. Trends Psychiatry Psychother. 2017;39(1):12-8. doi: 10.1590/2237-6089-2016-0004

8. Lichtman JH, Froelicher ES, Blumenthal JA, Carney RM, Doering LV, Frasure-Smith N, et al. Depression as a risk factor for poor prognosis among patients with acute coronary syndrome: systematic review and recommendations: a scientific statement from the American Heart Association. Circulation. 2014;129(12):1350-69. doi: 10.1161/CIR.0000000000000019

9. Wrenn KC, Mostofsky E, Tofler GH, Muller JE, Mittleman MA. Anxiety, anger, and mortality risk among survivors of myocardial infarction. Am J Med. 2013;126(12):1107-13. doi: 10.1016/j.amjmed.2013.07.022

10. Bandelow B, Michaelis S. Epidemiologia dos transtornos de ansiedade no século XXI. Diálogos Clin Neurosci [Internet]. 2015 [cited 2017 Oct 10];17(3):327-35. Available from: https://www.revistas.usp.br/revusp/article/download/28479/30333/

11. Meijer A, Conradi HJ, Bos EH, Thombs BD, van Melle JP, Jonge P. Associação prognóstica de depressão após infarto do miocárdio com mortalidade e eventos cardiovasculares: uma metanálise de 25 anos de pesquisa. Gen Hosp Psychiatry. 2011;33(3):203-16.

12. Roest AM, Zuidersma M, Jonge P. Infarto do miocárdio e transtorno de ansiedade generalizada: acompanhamento de 10 anos. Ir. J Psiquiatria. 2012;200:324-9. 


\section{AUTHORS' RESPONSE}

\section{Dear Professor Dulce Aparecida Barbosa}

Editor-in-Chief of Revista Brasileira de Enfermagem,

The notes show the interest of young researchers in the theme and the importance of Revista Brasileira de Enfermagem in disseminating knowledge.

In response to the notes, we emphasize that in relation to the suggested national studies, none of the three evaluated the impact of anxiety and depression on morbidity and mortality of patients with acute coronary syndrome. The first article entitled"Depression and Acute Coronary Ischemic Syndrome" ${ }^{\prime \prime 2}$ is a study that evaluated the prevalence of psychic depression in patients with acute coronary syndrome and the relationship of risk factors for coronary artery disease. In this context, this study aimed to evaluate the level of depressive symptoms of hospitalized patients with coronary artery disease, as well as the relationship of other cardiovascular risk factors with depression. In this context, this study aimed to assess the level of depressive symptoms in hospitalized patients with coronary artery disease, as well as the relationship of other cardiovascular risk factors with depression. The second article entitled "Depression and myocardial infarction"(3) is a literature review that addressed several aspects of the relationship between depression and acute coronary syndrome, such as the prevalence and diagnosis of depression in this population, pathophysiology of the disease, factors related factors that contribute to the emergence of depression and its relationship with heart disease and treatment. The third article mentioned, in turn, compares the symptoms of depression in three populations: hospitalized patients with acute myocardial infarction, cardiac patients in outpatient care, and population without a diagnosis of heart disease, making a relationship with quality of life ${ }^{(4)}$. In this sense, none of the three articles mentioned address the relationship between anxiety and depression in patients with acute coronary syndrome and morbidity and mortality of this population. They do not have the same objective as our article, which was to assess how much the anxiety and depression symptoms of patients who were hospitalized for acute coronary syndrome contributed to the need for myocardial revascularization, readmissions and mortality. In relation to the suggested descriptors, two of them are not appropriate: quality of life and risk factors. If you want to carry out studies for this purpose, we suggest that you use descriptors such as mortality, morbidity and readmissions.
The reference of the previous study that we used to support the level of anxiety and symptoms of depression is described in the method: "Data related to anxiety and depression were collected from the database of the previous study". This study evaluated, among other things, the level of anxiety and symptoms of depression in hospitalized patients with acute coronary syndrome. Data collected from this database were only those related to anxiety and depression ${ }^{(5)}$. In relation to losses from follow-up, it is already known that this type of study (cohort) can present losses of participants during the follow-up due to refusals to continue participating in the study, changes in addresses, among other factors. We authors, nevertheless, describe at the end of the discussion as one of the limitations of our study.

Concerning age, we do not divide by age groups, since there was no significant correlation between the levels of anxiety and depression with the increase in patients' morbidity and mortality. Furthermore, although this data appears only in the dissertation whose product was this article, when comparing whether there was a statistical difference between the age of those who reported having greater symptoms of depression with those who reported having less symptoms, it was observed that there was no statistical difference $(p=0.76)$. This same behavior was obtained between the highest and lowest anxiety levels $(p=0.70)$. We emphasize that this data was not presented because it is not the objective of the article. In this sense, there was no need for further analysis regarding age.

As for the collection of complementary data by telephone, we reinforce that the data collected were related to morbidity (need for myocardial revascularization and readmission) and mortality. Thus, there is no way for the patient or family member to have doubts if there was a need for surgery, for a new hospitalization or if the patient died. Emotional state, as described, does not interfere with these questions.

Finally, in relation to the follow-up time, as a retrospective cohort study was developed and because it is a product of a master's dissertation, it was not possible to increase the followup time. We also emphasize that, although the results show that there was no significant association between the levels of anxiety and symptoms of depression with the morbidity and mortality of patients, the proposed objective was achieved.

Therefore, as well stated, studies of this nature are important for the health area and thus, professionals who are interested in this topic can replicate the study, expanding the sample size.

\section{REFERENCES}

1. Altino DM, Martins LAN, Gonçalves MAB, Barros ALBL, Lopes JL. Impact of anxiety and depression on morbidity and mortality of patients with coronary syndrome. Rev Bras Enferm. 2018;71(6):3048-53.

2. De Mattos MA, Lougon M, Tura BR, Pereira BB. Depressão e Síndrome Isquêmica Coronariana Aguda. Revista da SOCERJ.2005;28(4):288-94.

3. Alves TCTF, Fráguas R, Wajngarten M. Depressão e infarto agudo do miocárdio. Rev. psiquiatr. clín. 2009;36(Suppl 3):88-92.

4. Lemos C, Gottschall CAM, Pellanda LC, Müller M. Associação entre depressão, ansiedade e qualidade de vida após infarto do miocárdio. Psicologia: Teoria e Pesquisa. 2008;24(4):471-6.

5. Lopes JL, Barbosa DA, Nogueira-Martins LA, Barros ALBL. Nursing guidance on bed baths to reduce anxiety. Rev Bras Enferm. 2015;68(3):437-43. 